\title{
ITINERARIO DE UNA POÉTICA NARRATIVA EN LAS OBRAS DE EDNODIO QUINTERO
}

\author{
POR \\ Blas Puente-Baldoceda \\ Northern Kentucky University
}

La línea de la vida (1988) del escritor venezolano Ednodio Quintero comprende una reescritura del primer libro de cuentos breves titulado La muerte viaja a caballo (1974) y un conjunto de textos más recientes que, según lo advierte el autor en una nota, responde a una nueva línea de escritura. En realidad, la estructura narrativa y el estilo de la primera parte, "Primeras historias", no difieren de la segunda parte "La línea de la vida", aunque se evidencia una cierta variación temática. En "Primeras historias" el autor implícito" se centra en temas tales como la muerte, el amor, la violencia, la soledad, lo telúrico y el tiempo, e incluso aborda al margen otros temás tales como el incesto, el sentimiento de culpabilidad, la hechicería, lo demoniaco y el exorcismo. En la primera parte la temática se desarrolla en tramas en las que predomina el conflicto individual e interindividual, mientras que en en el segunda cobra relieve la colectividad primigenia en búsqueda de una divinidad a través de la invención del mito, el ritual y la magia.

El rasgo distintivo en la organización de la trama en "Primeras historias" es el cierre de los cuentos cortos mediante un final sorpresivo. La revelación de gran efecto se logra

\footnotetext{
${ }^{1}$ El autor implícito es la imagen mental del autor real que todo lector construye a partir del texto literario. Rimmon-Kenan lo define precisamente como "una construcción que infiere y ensambla el lector a partir de los componentes del texto". Shlomith Rimmon-Kenan, Narrative Fiction: Contemporary Poetics (Londres: Methuen, 1983) 87. Los narratólogos también lo consideran como la conciencia responsable de organizar las normas ideológicas, estructurales y estilísticas del texto literario. Véase Wayne C. Booth (1961), Seymour Chatman (1987), Shlomith Rimmon-Kenan (1983), Susan Snaider Lanser (1981). Por otro lado, Chatman lo distingue claramente del narrador: "No es el narrador sino el principio que inventa al narrador y los demás componentes del texto narrativo. Se diferencia del narrador porque el autor implícito no enuncia: no tiene voz ni medios de comunicarse. Nos instruye en silencio, aunque es el artificio textual que organiza y selecciona las voces narrativas para el lector. Se comprende con claridad la noción de autor implícito si se compara los diferentes textos de un autor real, ya que estos presuponen diferentes autores implícitos". Seymour Chatman, Story and Discourse: Narrative Structure in Fiction and Film (1978); (Ithaca: Cornell University Press, 1987) 148. Por su parte, Genette puntualiza: "El autor implícito es lo que el texto nos da a conocer del autor real, y es una noción que el lector o el crítico debe tener en cuenta. Sin embargo, no me convence el hecho de que algunos críticos la consideran como una instancia narrativa, ya que esto significa multiplicar innecesarimante las instancias narrativas". Gérard Genette, Nouveau Discours (París: Seuil, 1983) 102. Las traducciones en el artículo son mías.
} 
en virtud a una dosificación concisa de los eventos y una gradual tensión dramática en la elaboración del suspenso, y este patrón estructural deviene reiterativo. Sin lugar a dudas, Quintero es un virtuoso de la narración breve gracias a una extraordinaria capacidad de síntesis y a una inteligente selección de los elementos relevantes. No obstante, en la estructuración de alguno de los cuentos es notoria la pauta borgeana: por ejemplo, la suplantación del soñador por el soñado, o del asesinado por el asesino, tal como ocurre en "El hermano siamés" y "La muerte viaja a caballo." Estos cuentos podrían formalizarse de la siguiente manera: $A>B=(B(A))$. Es decir, mediante pistas falsas se crea la expectativa de B; sin embargo, se produce $A$. Asimismo, el autor ensaya otras posiblidades de argumento como el esquema formal $\mathrm{A} 1+\mathrm{A} 2+\mathrm{A} 3 \ldots=(\mathrm{An}(\mathrm{B}))$ que opera en "El suicida", un cuento corto en el que se mencionan elementos relacionados con lo humano, pero el final es desconcertante: el protagonista del suicidio resulta ser un animal. Todas estas formas del relato podrían subsumirse dentro de la técnica de la inversión que contribuye a crear tensión narrativa. $^{2}$

En relación al registro estilístico, se nota en nivel paradigmático un predominio de la frase nominal con una adjetivación libresca y recargada en uno que otro fragmento, mientras que en el nivel sintagmático prevalece la yuxtaposición y la coordinación sintáctica, especialmente con un exceso de la ennumeración que por momentos adquiere una tonalidad monótona y atosigante Ahora bien, la metaforización abarca dos espacios semánticos: lo telúrico y lo onírico, ya que Quintero es un profundo conocedor de los elementos del paisaje del referente socio-histórico de su ficción. Más aun: el contenido de los cuentos cortos se enraiza en el acervo de la cultura popular y sus mitos, leyendas, fábulas, cuentos orales, etc. Sin embargo, el escritor venezolano no se limita a la relación del hombre y la naturaleza, sino que nos revela la psicología de sus personajes mediante una ingeniosa manipulación del lenguaje de los sueños.

En la mayoría de los cuentos breves los narradores son omniscientes y son referidos mediante la tercera persona gramatical. El registro estílistico se mantiene más o menos uniforme. Por su parte, los personajes reciben focalización cero o externa. ${ }^{3}$ Sin embargo,

\footnotetext{
2 Alazraki comenta sobre el modo de narración de "La forma de la espada" de Borges en estos términos: "La sorpresa que cierra el cuento puede producirse porque la inversión ha creado la necesidad de revertir los términos traidor/traicionado. A lo largo del relato el narrador ha dispuesto los hechos como una sucesion de actos preparatorios que inevitablemente conducen a la identidad del otro. La narración se justifica como reflejo invertido de ese otro que espera en el fondo del relato". Versiones, inversiones, reversiones. El espejo como modelo estructural del relato en los cuentos de Borges (Madrid: Gredos) 64. Esta apreciación crítica podría bien aplicarse a la estructura narrativa de algunos de los cuentos de Quintero.

${ }^{3}$ La focalización - denominada también "punto de vista" o "perspectiva" - es incluida dentro de la categoría narrativa de modo. La narración novelesca se nos presenta a través de la mediación de un punto de vista o perspectiva que adopta tres maneras: a) focalización cero: cuando el narrador dice más de lo que el personaje sabe; b) focalización interna: cuando el narrador dice lo que el personaje sabe y ve las cosas a través de esta conciencia individual; c) focalización externa: cuando el narrador sabe menos que el personaje y ve las cosas desde afuera sin poder penetrar los pensamientos y sentimientos ajenos. Es la llamada narración "objetiva" o "behaviorista" Genette, Narrative Discourse. Traducida por Jonathan Culler (1972); (Ithaca: Cornell University Press, 1980) 189-90.
} 
la esporádica focalización interna se expresa mediante discurso indirecto libre. Cuatro cuentos - "Antares", "El hermano siamés", "Gallo pinto" y "La muerte viaja a caballo"son narrados en primera persona, y en los dos primeros existe una variación de la primera persona singular a la primera persona plural con el propósito de respaldar los hechos narrados mediante la sabiduría colectiva.

En su segundo libro de cuentos, Volveré con mis perros (1975), se nota la impronta de Juan Carlos Onetti en la configuración de los personajes que protagonizan tramas sobre el sexo, la locura, el absurdo, el homicidio, la muerte, el deterioro humano, el azar, el destino, la infancia, el retorno al pasado, el adulterio, la pederastia, las relaciones anómalas entre padre e hijo, y los mecanismos inherentes a la ficción. La pérdida de la pureza infantil por el brutal descubrimiento del sexo, provocada por el irresponsable egoísmo de padres adúlteros, genera experiencias traumáticas que sumergen a los personajes en el pasado para indagar las causas patológicas de la infelicidad. La conducta sexual se manifiesta con una exacerbada violencia en ambos sexos, aunque de manera paradojal conduce a la pareja a una suerte de catarsis en algunos casos; o a una realización plena, en otros. EI conflicto entre padre e hijo se resuelve en futuros actos de venganza cuando el supuesto agresor cree que todo quedó sumido en el olvido y el agredido se propone eliminarlo porque se niega admitir la existencia de un doble. En el cuento "Valdemar Lunes, el inmortal", el tema del doble se complementa con la circularidad del tiempo a la manera borgeana. Por otro lado, el crimen es concebido como un absurdo sacrificio ritual: los homicidas son orates que están sujetos a designios prefijados por una misteriosa voluntad omnipotente. De cualquier modo, la descripción de la sórdida degradación humana que conduce a la insanía se contrasta con la valoración de la condición animal. Este deterioro humano no sólo se manifiesta en la trama sino en la organización léxica del discurso: en uno de los cuentos, por ejemplo, se registra una serie de lexemas tales como "sombríos", "sórdidos", "horrible", "infortunio", "maldad", "insanía", "oscuro" que apuntan obviamente a una constelación semántica que se subsume en el lexema "deterioro", la cual conforma una configuración discursiva conspicua en la mayoría de los cuentos. La premonición de la proximidad de la muerte se atenúa con la evocación de los dulces momentos de la infancia y es obvia la obsesión con el tiempo por la frecuencia con que se menciona el contraste temporal entre el presente y el pasado. El problema de la muerte es tratado mediante una forma narrativa compleja: la manipulación de diferentes planos de la realidad ficticia. Por ejemplo, en lugar del esperado deceso de uno de los personajes ficticios, el autor es asesinado y la identidad del homicida se diluye en las brumas de la ambigüedad. Este afán de acrecentar la intriga tanto temática como formalmente llega a extremos crípticos puesto que en algunos de los textos es inútil cualquier intento de interpretación por parte del lector.

Desde el brevísimo texto "La cacería", lo onírico se constituye en una recurso para la creación de una fantasmagoría alucinante donde la conciencia de los narradoresprotagonistas da rienda suelta a la evocaciones delirantes en las que prima una aparente asociación inconexa e impredecible. Por otro lado, en cuanto al tratamiento narrativo Quintero muestra una incuestionable destreza en hilvanar eventos con una creciente intensificación dramática que logra alcanzar momentos climáticos cuyo desenlace produce una suerte de purificación en los personajes. La remembranza es convulsiva, 
pesadillesca, especialmente cuando incide sobre las emociones, sentimientos y voliciones de los protagonistas. Es más, en la utilización de elemento onírico, el escritor Quintero elabora imágenes que se ubican en una zona difusa entre el sueño/pesadilla y la vigilia. Esta especie de automatismo de corte surrealista exige ciertas experimentaciones de cuño vanguardista tanto en el lenguaje como en la estructura narrativa. Por ejemplo, algunos de los cuentos presentan las formas retrospectivas de la primera persona y el monólogo interior, con un registro estilístico coloquial que exige rupturas de orden prosódico y sintáctico. En la prosa de Volveré con mis perros es obvio el esfuerzo por despojarse de la retórica un tanto ampulosa y preciosista que caracteriza sus primeros escritos en los cuales son frecuentes los clichés o las frases trilladas; al contrario, el discurso oral del segundo libro fluye con mayor espontaneidad, aunque esporádicamente se producen intromisiones del registro libresco de un narrador omnisciente. La nueva prosodia exige, por lo tanto, una reformulación de las pausas de los signos de puntuación. Asimismo, el autor inserta parlamentos de los personajes en cursiva para enfatizar la oralidad en su escritura. Por otro lado, además de la primera personal gramatical, se advierte el uso de otras personas gramaticales dentro de la misma narración: en algunos cuentos se observa repentina variación de la primera persona plural a la segunda persona singular y a la tercera persona singular. Además, los cambios de focalización se correlaciona con el registro lingüístico; por ejemplo, en el caso de los personajes niños se maneja la focalización interna con el uso de diminutivos como marcas discursivas. Este afán experimentalista se manifiesta, por otro lado, en la estructuración de la trama, ya que los bruscos cambios de escenas, las fracturas temporales de las retrospecciones y anticipaciones, las asociaciones inconexas, parecieran obedecer los impredecibles lineamientos del sueño y la pesadilla. Esta estructuración onírica de la trama en los cuentos discurre de manera diáfana en la mayor parte del libro, aunque en algunos textos deviene en una estructura realmente críptica - tal es el caso de "Jaque a la sota de copas"- donde se insinúan motivos cuyo simbolismo es indescifrable.

En la colección de ocho textos titulado El agresor cotidiano (1978), Quintero se muestra como un consumado artífice del cuento breve al mismo tiempo que ensaya una prosa depurada de la retórica de lugares comunes, aunque maneja el mismo procedimiento estilístico de la coordinación, la yuxtaposición y la enumeración, pero esta vez con un mejor control del efecto monocorde que produce su prosa en otras páginas de su obra. En cuanto a la persona gramatical de la narración — a excepción del cuento "Adiós al amigo", en el cual se alterna el uso de la primera persona singular y plural con el uso de la segunda persona singular - los demás cuentos son narrados en primera persona singular. La organización de la trama obedece mayormente a un delineamiento de carácter silogístico ya que las escasas escenas giran en torno a los ejes de la inversión, el contraste, la contradicción, etc., pero no por ello carentes de complejidad debido a la simultaneidad y/ o superposición de planos escénicos. Este afán logicista se manifiesta incluso en algunos segmentos textuales en que las reflexiones del narrador, ya sea en forma de comentario o generalización, se vierte en una prosa ensayística, en contraste con segmentos de prosa pletórica de imágenes poéticas, fruto de una exquisita sensibilidad frente al paisaje, la flora, la fauna y el clima del referente socio-histórico que se recrea en la ficción. 
Ahora bien, en la temática del libro el ingrediente fantástico se desliza en la vida cotidiana con mayor naturalidad y logra suspender la credibilidad del lector. En el cuento " $33 \mathrm{~mm}$ " se narra en una secuencia de dos escenas: la cámara fotográfica, en vez de captar las imágenes de la mujer que posa desnuda frente al fotógrafo, ha registrado las imágenes de su trajín hacia el estudio bajo una tormenta de lluvia, y luego una de ellas -llamada "relámpago-tigre" - fulmina al fotógrafo en el momento de revelar el rollo. En "Álbum familiar", una anciana confunde al hijo muerto con un perro lanudo. El narrador propone dos hipótesis: la anciana delira o disimula su ceguera. Abrumado por la parafernalia canina que abunda en la casa, el narrador queda convencido sobre la insanía de la pareja que lo hospeda y propone dos posibilidades de interpretación: la pareja adoptó un perro ovejero o la anciana, en realidad, lo parió. Más aun: existe una tercera posibilidad: todos, incluido el narrador, son, en realidad, perros porque un buen día amanecen ladrando. El elemento fantástico es verosímil porque el razonamiento lógico -el juego de premisas y conclusiones- sugiere tácitamente el enloquecimiento paulatino del narrador, y el lector concluye que la razón y la locura son el anverso y el reverso de la naturaleza humana. Aunque postuladas en una relación de contraste, los elementos opuestos se fusionan dialécticamente al término de la narración. En "El zarpazo" el afán silogístico se revela en el estilo ensayístico, aunque, al mismo tiempo, el impresionismo poético de las descripciones del medio circundante establece una suerte de contrapunto dentro de la estructura textual. Un observador, cuya entidad se supone humana, registra los movimientos mínimos del zamuro, una ave que augura la muerte. El final es impactante debido a las pistas falsas que distraen al lector: el que muere es el zamuro, ya que el observador se adelanta en contrarrestar la muerte con el poder de la mente. En "Costumbres", un estudiante - ya sea por provocación o exhibicionismo- decide pasearse desnudo por la ciudad. Desilusionado por la total indiferencia de los peatones, vuelve a vestirse antes de su salida matutina a la calle, y los peatones que trajinan desnudos lo miran escandalizados. Esta idea de que lo insólito de ayer deviene la norma de hoy se elabora mediante un esquema contradictorio ya que ahora la desnudez no causa sorpresa, pero sí la vestimenta. El título "Adiós al amigo" es en sí irónico, ya que el narrador e Ixa entierran vivo al amigo actor cuya precocidad artística se adereza con la leyenda del abandono paterno y de una madre prostituta, no de otra manera se explica el ocultamiento de su verdadera identidad en las máscaras de la actuación y en su recóndito terror a la felicidad. La primera escena transcurre en el cementerio: el narrador asume el rol de un testigo objetivo y describe el entierro mientras rememora la infancia del protagonista, su carrera artística, sus problemas, y la última orgía en su apartamento cuando los amigos - Juan, Margot, Judith, Ixa, su amante, y el narrador, quienes le profesan una resentida admiración - lo dejan dormido en estado de ebriedad. La segunda escena ocurre en una sala de cine al que acuden el narrador y la infiel Ixa después del funeral en el cementerio y ven una película protagonizada por el amigo que probablemente está a punto de morir por el enrarecimiento del oxígeno en el ataúd, y cuya muerte es precedida por el suicidio de una admiradora suya antes de que culmine la función cinematográfica. Esta intrincada superposición de planos escénicos conduce al lector a especular creativamente en qué momento el narrador e Ixa deciden la muerte del protagonista y cómo la llevan a cabo. En "Parque A.M." se repite en versión una constante temática de Quintero: la evocación de los remotos recuerdos gratos antes de la muerte. Antes de 
ahorcarse, un hombre evoca desde un árbol el primer amor de su niñez, Lucía, y, a modo de contraste, narra no sólo el itinerario en coche de su esposa y su hija - llamada también Lucía- hacia un parque, sino también escenas de tipo surrealista - como por ejemplo, una mujer desnuda con un collar de perlas que describe la biografía del hombre de marras, conduce un coche color sangre con una oveja en el asiento posterior. En contraposición con la temática trágica, la narración se matiza con descripciones poéticas del paisaje. En "El agresor cotidiano" se incide nuevamente sobre el problema del doble pero esta vez se propone que la otredad es una fuerza enemiga que nos habita y si tratamos de eliminarla nos aniquilamos automáticamente. Finalmente,"María" es un cuento en el que se entrelazan las evocaciones sobre la infancia, la religión, la muerte y el amor. La atracción erótica que le produce la estatua de la virgen María se contrapone al amor platónico que le inspira secretamente la niña María, y esto se correlaciona con la oposición paradojal entre el lado angelical y el lado demoniaco que habitan en los niños. El cuestionamiento de los rituales religiosos - la confesión, la comunión - inculcados por la madre, contrasta con las conversaciones sobre la muerte que sostuvo con su padre antes del deceso de éste último. La pluma de zamuro - ave que presagia la muerte- que regala a María, sugiere la interdependencia de ambos temas en la cosmovisión del autor implícito.

La novela La danza del jaguar (1991) está conformada por cinco capítulos denominados Libros, cuya autonomía — según lo indica el editor en la presentación- es relativa ya que existen indicios textuales de que los cinco capítulos giran en torno al personaje Joe Miguel. En el Libro Uno titulado "El guerrero", la trama central es acerca del niño Joe Miguel que especula sobre la muerte de su madre y decide abandonar el pueblo después del asesinato de su padre por unos forasteros. Esta trama central se desdibuja entre las varias anécdotas marginales que ocurren en la diégesis ${ }^{4}$ - tales como el violinista que le concede el don de la invisibilidad o el rapto de una campesina por una pandilla de forajidos durante el día de Reyes - y entre otras que son resultado de una prolífica imaginación onírica - tales como el suicidio o la posible huida de su madre con los gitanos o sus viajes imaginarios que emprende gracias a la capacidad de volar. En todo caso, la actividad lúdica de soñar se funda en la idea de que el sueño ofrece las claves para entender el comportamiento humano. Por otra parte, las alusiones a Sinbad, los dragones, las sirenas, Troya, Rocinante, la Atlántida, los argonautas, inducen a suponer que la extraordinaria capacidad de fantasía se nutre en gran medida de la mitología y la literatura universal. De cualquier modo, en el mundo ficticio de Quintero confluyen obviamente dos vertientes lo fantástico y el realismo mágico- y en la reelaboración de ambas deja entrever por momentos una gran dosis de artificialidad. Con respecto al aspecto narrativo, "El guerrero" se vierte en una de las formas de la primera persona denominada memoria narrada que se singulariza por la presentación narrativa regulada por libre asociación de la memoria y lo onírico. En esta forma narrativa, los hechos narrados se suceden de manera descronologizada

\footnotetext{
${ }^{4}$ La narración produce el récit o texto narrativo que está conformado por la interrelación entre el discurso del narrador y el discurso de los actores. La histoire o diégèse o contenido narrativo está conformado por las acciones $\longrightarrow$ mundo narrado que es objeto del discurso del narrador-y los eventos evocados por el discurso de los actores -o mundo citado que es mencionado por el narrador mediante los verba dicendi y sentiendi.
} 
a un nivel de la macro-estructura textual, aunque a nivel de la micro-estructural temporal la secuencias de eventos se ajusta a una presentación narrativa realista puesto que se ciñe a la concepción tradicional de narrar que presupone la comunicación $\mathrm{y}$, por ende, la explicación de causas y efectos. ${ }^{5}$

En el Libro Dos, "Lección de física", las múltiples anécdotas se hilvanan en torno a un argumento central: el adolescente Joe Miguel no rinde un examen debido al insomnio de la noche anterior y obtiene permiso del profesor para regresar a su casa. En esta fase de su vida el personaje exhibe una mente inquisitiva, una facultad extraordinaria para la fabulación, una sensibilidad refinada hacia el paisaje cuyos matices cromáticos y sinestésicos se correlacionan con sus sentimientos y emociones - hecho que se explica por su origen montañés- y una proclividad hacia la fantasmagoria erótica y sexual. La fabulación incide no sólo ya en la obsesión de volar y ser invisible, sino en las travesías por espacios y tiempos siderales: imagina, por ejemplo, la vida de sus amigos en un futuro lejano después de retornar de un viaje por la Vía Láctea. Esta facilidad para crear constamente mundo imaginarios conduce al personaje a reflexionar sobre las fronteras entre la realidad y la ficción, entre la razón y la locura, entre las convenciones de la sociedad racional y la marginalidad de un soñador. El personaje, por otro lado, adopta un tono iconoclasta cuando desmistifica la historia oficial y sus magnos próceres, ridiculiza las vanidades de las castas sociales, y denuncia la represión fascista contra los judíos, palestinos, sudafricanos e indios. En este capítulo el autor implícito disemina claves que coadyuvan a una cabal comprensión de la novela: su afición por el psicoanálisis y el lenguaje de los sueños (el personaje menciona su familiaridad con la obra de Freud), su narcismo autoanalítico y el exceso de su fantasía, su pasión por el sonido y el significado de las palabras y por la construcción de un estilo. Estas claves se ilustran en las siguientes citas:

¿Cómo era que, buceando en el pozo turbio de los sueños, esquivando zonas minadas, revelando cicatrices ocultas, se podían extraer conclusiones acerca de la conducta de las personas? (36).

Yo era tolerante con mi pereza y mi desidia, exagerado en mis fantasías, prendado de los atributos que yo mismo me asignaba sin moderación (40).

Pájaros sueltos las palabras, dibujando en el aire figuras caprichosas, trazando signos que sugieren la presencia de un bisonte o las notas de una canción. Piedras preciosas las palabras (47).

\footnotetext{
${ }^{5}$ Dorrit Cohn sostiene que en "[s]uch a-chronological memory narrative ... maintain[s] a perfectly conventional narrative presentation but follow[s] an order determined ... by associative memory ... Memory narratives, in other words, far more readily disrupt the temporal macro-structure than the micro-structure of a text, revealing the tenacity of the link between realistic narrative presentation and chronological narrative sequence. As long as a narrator writes or speaks, he fashions a language based on communication: he presents, explains, links cause and effect - and thereby falls back on temporal order". Transparent Minds: Narrative Modes for Presenting Consciousness in Fiction (Princeton: Princeton University Press, 1978) 182-83.
} 
Joe, sosiégate. A ese ritmo de predicador evangélico con que desarrollas tu discurso, corres el riesgo de precipitarte en un acantilado verbal (73).

Por otro lado, el autor implícito se sirve de transfiguraciones de corte kafkiano -el personaje se convierte en un gato- para insertar anécdotas intradiegéticas ${ }^{6}$ subordinadas a la trama principal y en las que persisten dos temas recurrentes de libros anteriores: la muerte y la exploración de la mitología popular. El primero se manifiesta en el macabro plan de suicidarse y las especulaciones sobre las reacciones de Tomasa, su huésped; el segundo, en las siguientes historias: el incidente erótico con Aurora a quien le pide como regalo su panteleta para conservarlo hasta la muerte; los infortunios de sus tías, las mellizas Ramona y Eusebia; su búsqueda del brujo Abel para obtener el bálsamo que curará a su amante Digna Rosa, una paralítica ingeniosa que lo desvirga con el placer del sexo oral. Esta relación idílica - juntamente con sus otras excentricidades (la soledad, la lectura obsesiva y la masturbación) - acentúan la marginalidad del personaje. Ahora bien, en este capítulo Joe Miguel confiesa que escribe un diario en el cual registra sus "impresiones, algunos sueños y proyectos fantasiosos ... diálogos inconclusos, un tanto pretenciosos, con mi alter ego". Como puede apreciarse, la temática del diario coincide con el de la novela mediante el artificio textual mise en abyme. ${ }^{7}$ Es más: en este capítulo se inicia el proceso auto-reflexivo - llamado también metaliterario o narcisista- de la novela, que se manifiesta a través de una autoconciencia de las posibilidades de la imaginación creadora y de un cuestionamiento tanto de la representación ficticia como del potencial expresivo del lenguaje, de la eficacia de las técnicas narrativas y, sobre todo, de la función de escribir. ${ }^{8}$ Por ejemplo, el personaje es consciente no sólo de su habilidad para describir con plasticidad y colorido el paisaje del referente socio-histórico de su ficción sino de la exuberancia de su imaginación:

Haría un relato exultante y minucioso de la travesía. Con descripciones detalladas del paisaje, tomando en cuenta los colores del cielo y de los árboles, la calidad del aire, la presencia de algún pájaro y las variaciones de la luz. En cuanto a los personajes, me

\footnotetext{
${ }^{6}$ Genette distingue dos niveles narrativos: extradiegético e intradiegético. El primer nivel narrativo que ocupa una posición superior con respecto a otros niveles narrativos y que controla el proceso mismo de la narración se denomina extradiegético; mientras que la narración de un personaje dentro del primer nivel narrativo se coloca en un segundo nivel narrativo y se denomina intradiegética: Narrative 227-31. Por su parte, Rimmon-Kenan comenta, asimismo, sobre las relaciones de subordinación entre estos niveles narrativos y señala tres funciones del segundo nivel narrativo (o intradiegético) con respecto al primer nivel (o extradiegético): función accional, función explicativa y función temática: Narrative Fiction 91-94.

${ }^{7}$ Una definición pluralística de mise in abyme es la siguiente: "[A] mise in abyme is any internal mirror that reflects the whole of the narrative by simple, repeated or 'specious' (o paradoxical) duplication." Lucien Dallenbach, The Mirror in the Text, traducido por Jeremy Whiteley con Emma Hughes (Chicago: Chicago University Press) 36.

${ }^{8}$ Elzbieta Sklodoska elabora una adecuada selección de las denominaciones más comunes y los rasgos más revelantes que caracterizan a la novela autorreflexiva y, asismismo, discute exhaustivamente sus relaciones con la parodia. La parodia en la nueva novela hispanoamericana (Amsterdam/Philadelphia: John Benjamins Publishing Company, 1991) 63-5.
} 
ocuparía de sus gestos más característicos, de los matices de la voz, incluso de sus vestimentas. Y cuando surgiera, radiante, mi amada de las regiones cálidas, dejaría volar la imaginación (117-18).

Esta auto-reflexividad literaria se proyecta hacia el cuestionamiento de la eficacia figurativa y simbólica del lenguaje como un vehículo de expresión del caos de naturaleza humana, y, asimismo, incide sobre los riesgos del acto de escribir: el afán de perfección, frustración y la impotencia:

No quise escribir nada en el diario, ni una palabra escribí. Ocurren cosas de las que no se debe hablar. De nada serviría una relación coherente, pues no existe orden ni secuencias lógicas en el caos interior. Las metáforas más agudas se convierten en aproximaciones desteñidas. El lenguaje simbólico es un recurso ineficaz, pues las máscaras acaban por sofocar. Lo mejor es callar (118-119).

Luego de leer un par de veces el comienzo de aquella historia bucólica, sólo persistían algunas líneas que describían con mediano acierto un atardecer. Una tercera lectura borraría el sol y las colinas, y haría trizas una metáfora infeliz en la que se comparaba el color de las nubes con las encías rosas de la princesa. Decidí postergar para tiempos mejores mi afición por la narrativa (122).

El Libro Tres, titulado "En la tierra de nadie", presenta una estructura compleja. El adulto Joe Miguel narra sus evocaciones sobre sus aventuras sexuales en Europa mientras descansa en una hamaca durante un paseo campestre en compañía de su amigo Raymond. Los diversos escenarios - París, Amsterdam Venecia, Zagreb, Stuttgart-y las peripecias con sus varias amantes - Dunia, Ethel, Susana, Marysia, Felice, Sofia - se narran mediante retrospecciones (analepsis) y anticipaciones (prolepsis) ${ }^{9}$ que ejecuta Joe Miguel mientras espera por Elissa, su amante principal, en dos escenarios: una estación de tren y una plaza parisinos. Desde estas localizaciones la instancia narrativa juega con las transposiciones temporales en diferentes formas discursivas y registros lingüísticos. Mientras en las retrospecciones el autor implícito utiliza los tiempos del pasado de la memoria narrada, los soliloquios durante las esperas son narradas en presente evocativo mediante la forma denominada memoria monologada: una especie de solipsismo mnemotécnico descronologizado más o menos al modo de una autoconfesión. ${ }^{10}$ Ambas formas coinciden en la tono humorístico, irónico, lúdico que se mantiene a lo largo el discurso narrativo. La marginalidad de Joe Miguel en el continente europeo se manifiesta no sólo en la extravagancia tanto en la vestimenta como en la actuación, sino también en la imagen que

\footnotetext{
${ }^{9}$ Genette teoriza sobre las disrupciones temporales o anacronía que se manifiestan en la estructura narrativa. Éstas son de dos clases: analepsias (retrospecciones) y prolepsias (anticipaciones): Narrative $25-85$.

${ }^{10}$ Cohn indica: "[T]his imitation of a solipsistic process imposses not only a fractured chronology, but also a fragmentary coverage ... The only temporal continuity that memory monologues present is the continuity of the spontaneously remembering mind. ... [T] he mind is trained exclusively on the past, the remembered events are tied only to each other, and not to a chronologically evolving time-span of silent locution", 184-85.
} 
proyecta en los demás: un insaciable sibarita que se solaza con las más escandalosas prácticas sexuales (fetichismo, contranatura, masturbación, lesbianismo, sadismo, coito grupal, etc.), a tal punto que se autocritica por boca de Elissa: "Me acusaría de pornógrafo, chapucero y fabulador, y se presentará a sí misma como víctima de mi crueldad mental" (177). En realidad, un catálogo más detallado de calificativos formulados por Elissa sirve para caracterizar a Joe Miguel:

Me llamó falsario, pervertido, falsificador. Corruptor de menores, sádico, machista, falócrata, masturbador insomne. Santurrón, enano, escribidor chapucero, cobarde, embustero, fanfarrón. Católico hipócrita, lamecucas y traidor. Me asignó tantos atributos -éstos y muchos más- que me imaginé a Musil levantándose de sus cenizas (esparcidas al voleo en un bosque de Ginebra) para protestar (189).

Por otro lado, Joe Miguel ostenta un gran conocimiento de la pintura, el cine, la música y la literatura universal. Con respecto a lo último, en el texto se hallan referencias a Kafka, Woolf, Man, Capote, Genet, Papillon, Sartre, Fourier, Nabokov, Brecht, Hšlderlin, Gombriwicz, Musil, a quienes recurre Joe Miguel no sólo con el propósito de demostrar su bagaje literario sino como un instrumento retórico para reforzar sus ideas o justificar sus sentimientos o acciones. Por otro lado, Joe Miguel emite algunas autocríticas como, por ejemplo, a las deficiencias de su rol como personaje:

Fuera del escenario he tenido que representarme a mí mismo, y no creo haberlo hecho tan mal. Algunos de mis gestos los imito a la perfección. Pero en conjunto soy infiel al personaje. No comparto sus manías persecutorias ni sus afanes de grandeza. Detesto su debilidad. Y su melancolía incurable me irrita tanto como a él (160).

Así, pues, debido la asociación libre del discurrir mental y a la inagotable actividad onírica, Joe Miguel abruma al lector con una incontrolable proliferación de evocaciones y fantasmagorías alucinantes mediante un lenguaje cuya espontaneidad languidece por momentos y se contamina con la rigidez del estilo culto de la tradición literaria. La fantasía alucinada de Joe Miguel se desborda hacia extremos inverosímiles: se convierte en un perro ducho en el arte de soñar para narrar sus peripecias en un campo de batalla de la Segunda Guerra Mundial, o imagina el hipotético juzgamiento al que es sometido por haber violado a una campesina a orillas de un río, o elabora y atribuye soliloquios a sus amantes. No obstante, el frenesí de una imaginación aluvial se sujeta al incesante cuestionamiento por parte del alter ego del personaje-narrador que a veces adopta la entidad del arcángel San Gabriel, la cual no es sino una de las máscaras que usa el autor implícito para autocriticar una serie de rasgos negativos del estilo y la composición de la novela y, asimismo, la verosimilitud de una ficción:

vacilante, enrevesada ... deshilachada, confusa, como si atravesara manuscritos antiguos protegidos por una cubierta de cuero de res ... que pondría en fuga a los más valerosos escuchas, e incluso los sordos expresarían su aburrimiento con bostezos de cocodrilo. Si el infeliz tuviera conciencia del poder dispensador y anestesiante de su torrente verbal, callaría de una buena vez (165). 
Los recuerdos se suceden sin orden ni concierto como si alguien los revolviera en el caldero de una bruja. Los rostros giran en torbellino, se entrecruzan y se superponen, cambian a una velocidad de vértigo - semejante a un juego de un ilusionista que va extrayendo figuras de su boca, de sus bolsillos y del aire (176).

¿Sería acaso ella una mentira total? ¿Existía de verdad? Yo no tenía ninguna prueba de su existencia, pues de la memoria no se puede confiar (181).

"Caída libre", el Libro Cuatro, es el texto más breve dentro del conjunto y su trama ligeramente detectivesca carece de complejidad: Joe Miguel se salva de morir a consecuencia de un accidente automovilístico gracias a la intervencón de un cirujano que ha encontrado entre las pertenencias de su paciente objetos femeninos que comprometen a éste último con el brutal asesinado de su amante Helena de Abdiján. Sin embargo, Joe Miguel se propone destruir la celada del "detective disfrazado de galeno", con una coartada: la occisa no es su amante sino su madre, y luego se las ingenia para huir del hospital. Ahora bien, no es tanto en la originalidad de la anécdota sino en la estructura del relato donde es necesario explorar las estrategias narrativas del autor implícito, especialmente en la estrategias discursivas de la organización temporal. En primer lugar, antes de revelarse el lugar donde se encuentra postrado Joe Miguel, su imaginación juega con varias posibilidades escénicas: es un herido que convalece de un apuñalamiento en la garganta y en el cuello y que está custodiada por cuatro personas (uno de ellos parece un gigante zulú por lo que Joe Miguel infiere de que vino a refugiarse al Africa occidental huyendo de la peste o el invierno nuclear o de su amante, Helena de Abdiján); o es un niño que delira con la fiebre y ve demonios, duendes, ángeles y que al salir a un patio sufre una caída (la mención del padre que lee, el abuelo que posee una biblioteca y de Rosalía que cuida de su orfandad, permite identificarlo el infante Joe Miguel); o es un prisionero torturado por unos esbirros enmascarados. Al cabo de este virtuosismo de la imaginación, el lector se entera finalmente de que Joe Miguel se encuentra postrado en una camilla en la habitación de un hospital. De manera imprevista, la narración en tiempo presente (además del futuro y el condicional) se convierte en una narración en tiempo pasado, lo cual indica que ópese a la sincronización del proceso narrativo y la experiencia de los hechos narrados (es decir, de la verbalización y la acción) - no se trata de un monólogo interior autónomo sino de una narración retrospectiva en presente evocativo. ${ }^{11}$ No es una silenciosa y fortuita autoconfesión enfocada

\footnotetext{
11 "This 'evocative' present -as I prefer to call the narrative present in a first-person context, though it must logically refer to a past experience- momentarily creates an illusion ("as if") coincide of two time-levels, literally 'evoking' the narrated moment at the moment of narration. And this apparent synchronization then makes the language of the text look to the 'real' synchronization of an autonomous monologue text": Cohn 189. Además de la sincronización de la verbalización con la percepción o lo experimentado, la narratología señala otras características del monólogo interior autónomo: "a chronological presentation of past events (the temporal sequence of past events yields to temporal sequence of present remembrance, and the past is thereby radically dechronologized), focus on the moment of locution, non-communicative language patterns, annulment of a realistic presentation, random thought, continuous evolvement of the discourse in punctual or instant present, etc."
} 
en la enunciación, sino una narración explícita de los eventos mediante explicación de causas y efectos; en otros términos, el texto es una narración en primera persona que supone un lector implícito. ${ }^{12}$

En el Libro Cinco, "Joe en la selva", el autor implícito insiste en la temática de la locura, las relaciones traumáticas de un infante con su padre, sus encuentros eróticos, el sueño, las alucinaciones de imaginación y la autorreflexividad literaria, e incursiona de manera tangencial en las relaciones humanas de la amistad y del matrimonio. Por otra parte, en el aspecto técnico continúa experimentado con la ubicuidad temporal del relato - por ejemplo, los planos temporales del presente narrativo y del pasado retrospectivo se invierten; con la inclusión de narraciones intradiegéticas - por ejemplo, el relato de su amigo Nick; y, finalmente, con la polifonía de registros estilísticos y la variedad genérica - por ejemplo, se incluye un poema. En cuanto a la autorreflexividad literaria, continúa el esfuerzo de desconstruir irónicamente el estilo y la estructura de su novela mediante el diálogo entre Joe Miguel y su alter ego. Es más: si seguimos las conclusiones teóricas de la revisión crítica que realiza Sklodowska sobre la parodía, podría asumirse que el autor implícito, consecuente con la autorreflexividad, autoparodia el estilo, ${ }^{13}$ la estructura narrativa y la construcción de personajes en la novela. Por ejemplo: aunque se pone en relieve el discurso oral de Joaquín, las características atribuidas a este personaje podrían referirse a la clásica prescripción estilística que subyace a uno de los registros de la novela:

Aunque apenas sabía escribir, Joaquín se expresaba con propiedad y corrección, utilizando un léxico amplio, sustancioso y variado, ubicando cada palabra en el lugar preciso y dando a cada frase el sentido y la entonación acordes con el discurso global (293).

Pues bien, en este capítulo el lector el lector corrobora la sospecha de que Joe Miguel es, en realidad, un escritor extremadamente exigente en cuanto a la creación de la forma literaria. Más aun: asume la creatividad con un gran sentido lúdico gracias a los atributos del humor y la ironía. Por esta razón, es capaz de parodiar el pre-texto que obedece ciegamente a la prescripción tradicional de "escribir bien" y de confrontarlo estilísticamente con la búsqueda de un nuevo modo "esencial":

\footnotetext{
${ }^{12}$ Con respecto al lector implícito, Genette afirma lo siguiente: "The author of narrative, like every author, addresses a reader who does not yet exist at the moment the author is addressing him, and who may never exist. Contrary to the implied author, who is the idea, in the reader's head, of a real author, the implied reader is the idea, in the real author's head, of a possible reader ... Until the recipient reads it ... however definite the recipient may be as a person, he remains potential as a reader. So perhaps it would positively be better to rechristen 'implied reader' potential reader": Narrative 149.

${ }^{13}$ Este cuestionamiento de los propios recursos estilísticos y técnicos mediante la inversión irónica y la actitud crítica podrían entenderse mejor con la siguiente aclaración: "Such could almost be considered self-parodic in that it calls into question ... its own identity. Self-parody in this sense is not just an artist's way of disowning earlier [style]. It is a way of creating a form out of the questioning of the very act of aesthetic production". Linda Hutcheon, "Modern Parody and Bakhtin", Gary Saul Morson y Caryl Emerseon, editores, Rethinking Bakhtin. Extension and Challenges (Evanston, Illinois: Northwestern University Press) 91.
} 
Ya no me interesan las frases perfectas, los temas ingeniosos rematados con un inesperado final, las metáforas brillantes, el estilo logrado a punta de cincel. Sólo aspiraba, en mi solitaria cacería, encontrarme cara a cara con la palabra esencial, y atraparla en mi red o ensartarla en mi puñal (305).

Sin embargo, Joe Miguel se contradice en cierto modo ya que en otra parte de la novela declara que posee un modo original de escribir y que no necesita la influencia de los pilares de la literatura universal — como, por ejemplo, un James Joyce, a quien cree conocer profundamente:

Me conozco al dedillo ese sendero trillado: el dédalo de Dublin. Caminaría por él a ciegas, sin hilo ni bastón. Pero no me interesa andar en pellejo ajeno, aun cuando me calce bien. Prefiero mi propio y oscuro y luminoso laberinto (275).

Más aun: consciente de su talento artístico Joe Miguel no escatima esfuerzos para alardear sobre el supremo poder de la literatura para derrotar los obstáculos de la realidad:

Si la palabra es una flecha untada con curare, me escudo tras la metáfora, tenso la cuerda, renuevo mi carcaj. ¡Alla vá! Los enemigos más empecinados abandonan sus trincheras (263-64).

Y para culminar esta aproximación al aspecto autorreflexivo de la narrativa del escritor Quintero, sólo resta mencionar la reacción de Joe Miguel hacia los críticos que se atreven a poner tela de juicio la verosimilitud de su mundo ficticio:

Por indicaciones de un amigo envié un manojo de cuartillas a una editorial. Se trataba de un escrito delirante, en el cual mi amigo, quizá por miopía o generosidad, había encontrado algún mérito. El ritmo trepidante de la prosa o algo así. ¿Qué querría decir? Yo, por supuesto, no me hice ninguna ilusión. Me devolvieron mis papeles y, no sé si por descuido o maldad, anexaron las "apreciaciones" de los lectores, que en sendos plumazos de tres cuartos de página despachaban mis "Sueños de halcón". Uno de los argumentos esgrimido por el más encarnizado de los jueces - creo que se trataba de una dama cincuentona de pétreo apellido - me produjo un ataque de risa que por poco me manda al hospital. Escribía la celosa señora lo siguiente: "La obra se resiente por inverosímil. El novel autor, valiéndose de metáforas en desuso, describe a una mujer de ojos azules. $\mathrm{Y}$ es bien sabido que en Venezuela no existen personas con ojos de ese color". Tampoco, señora, existen ni amazonas ni dragones de jardín (305-05).

A modo de recapitulación, podría asumirse que la exuberante imaginación del escritor Ednodio Quintero se ubica a horcajadas entre el realismo mágico y el neofantástico para construir una obra en base al gran dominio del código onírico, la descripción poética del paisaje, la exploración del acervo de la cultura popular, el conocimiento de la patología humana, la reflexión sobre arte de la ficción y el fenómeno literario. Esta rica temática se vierte en una narrativa en la que destacan la gran maestría en el cuento breve, el hábil manejo de complejas técnicas en la estructura temporal del relato, la suficiente flexibilidad lingüística que le posibilita la manipulación de diversas estrategias discursivas y registros 
estilísticos. No obstante, cabría señalar que el itinerario de una poética narrativa del escritor Ednodio Quintero —o si se quiere, su búsqueda de la "palabra esencial"- no ha culminado, pero no cabe duda que la "palabra esencial" logrará cristalizarse en obras futuras, ya que su talento en el arte de narrar es incuestionable.

\section{BIBLIOGRAFÍA}

Alazraki, Jaime. Versiones, inversiones, reversiones. El espejo como modelo estructural del relato en los cuentos de Borges. Madrid: Gredos, 1977.

Booth, Wayne C. The Rhetoric of Fiction. Chicago: University of Chicago Press, 1961. Chatman, Seymour. Story and Discourse: Narrative Structures in Fiction and Film (1978), Ithaca: Cornell University Press, 1980.

Cohn, Dorrit. Transparent Minds: Narrative Models for Presenting Consciousness in Fiction. Princeton: Princeton University Press, 1957.

DŠllenbach, Lucien. The Mirror in the Text. Traducción por Jeremy Whiteley y Emma Hughes. Chicago: Chicago University Press, 1989.

Hutcheon, Linda. "Modern Parody and Bakhtin". Gary Saul Morson y Caryl Emerson (editores), Rethinking Bakhtin. Extensions and Challenges. Evanston, Illinois: Northwestern University Press, 1989.

Quintero, Ednodio. La linea de la vida. Caracas: Fundarte, 1988. Volveré como mis perros. Caracas: Monte Ávila, 1975. El agresor cotidiano. Caracas: Fundarte, 1978. La danza del jaguar. Caracas: Monte Ávila, 1991.

Rimmon-Kenan, Shlomith. Narrative Fiction: Contemporary Poetics. Londres: Methuen, 1983.

Sklodowska, Elzbieta. La parodia en la nueva novela hispanoamericana. Amsterdam/ Philadelphia: John Benjamins Publishing Company, 1991. 